\title{
A narrative approach to Strategy as Practice: strategy making from texts and narratives
}

\author{
VALÉRIE-INÈS DE LA VILLE and \\ ELÉONORE MOUNOUD
}

\begin{abstract}
The narrativizing of practices is a textual 'way of operating', having its own procedures and tactics. [...] Shouldn't we recognize its scientific legitimacy by assuming that instead of being a remainder that cannot be, or has not yet been, eliminated from discourse, narrativity has a necessary function in it, and that a theory of narration is indissociable from a theory of practices, as its condition as well as its production. (de Certeau 1988: 78)
\end{abstract}

\section{Introduction}

The Strategy as Practice approach requires a close and detailed scrutiny by researchers on practitioners' activities. This micro-level of study enables us to depart from the traditional procedures and delve into the 'internal life of the process', to study in more details 'individual' rather than 'organizational' performance (Samra-Fredericks 2003). Moving attention away from macro-processes towards various aspects of the minutiae of strategy making has changed the discourse used by researchers to explain how strategy is conceived, explained and communicated (Whittington 2007). In practice, strategy is still essentially considered as micro-processes - i.e. the actual activities carried out by individuals within their organized contexts.

Although social practice theory tends to emphasize the tacit and informal dimensions of practices and praxis, Strategy as Practice research tends to focus much more on explicit practices, especially on operating procedures and standards (Jarzabkowski 2004, 2005), norms of appropriate strategic behaviour set by industry recipes (Spender 1989) and legitimizing discourses (Barry and Elmes 1997). Besides, while social practice theory advocates 'agency' for everyone in everyday life, Strategy as Practice research pays attention mainly to special events (Hendry and Seidl 2000) and top management personnel (Samra-Fredericks 2003). Thus the approach's achievement has been a change in the method of observing a phenomenon's processes, and not the basic categories of thought. It can be said that one pitfall of the Strategy as Practice approach is to focus only on the visible part of the iceberg: people, events and explicit tools. The actual practice in itself has not been sufficiently investigated.

Furthermore, focusing on micro-activities leaves the macro-micro distinction intact, but raises the subsequent problem of linking individual actions to macro outcomes. Making a 'practice turn' in strategy research requires not only knitting together 'micro-practices' and 'macro-outcomes', but also avoiding being caught in the trap of considering practices as just something people do. Practices are construed as social skills that have been culturally acquired, hence unconsciously absorbed and embodied. This compels us to take the dynamic and emerging fields of practices as the starting point for analysis, thereby getting by with the usual macromicro distinction. Hence, Chia and MacKay's (2007) call for shifting the focus of analysis 'from individual strategists to the historically and culturally transmitted fields of practice'. Schatzki (2005) proposes that we should view practices as relational sites in which events, entities and meanings compose one another. The challenge is now to overcome the prevalent individualistic focus on micro-level managerial activities and roles, which 
leaves a mass of larger social issues melting into the under-theorized, all-encompassing category of 'context' (Tsoukas 1994; Willmott 1997).

Following the Heiddegerian view, Chia and Holt argue that the dominant 'building' mode of strategy making, in which actors are distinct entities deliberately engaging in purposeful strategic activities, is actually derived from a more basic 'dwelling' mode in which strategy making emerges nondeliberately through everyday practical 'coping'. Practical 'coping' is rooted in social practices. Social practices are identity-forming and strategysetting activities. They provide individuals with resources to interpret and improvise their role; they shape the scope and the extent of their exploratory activities and initiatives to cope with the ongoing flow of organizational development (Chia and Holt 2006). Mundane practical 'coping' can produce unexpected and strategically important outcomes, as shown in the famous example of Honda's success in the USA (Pascale 1984), in Regnér's (2003) uncovering of local improvisation at the periphery of corporate reach, in de La Ville's (2006) work on emerging technological strategies in a start-up, and in Rouleau's (2005) analysis of strategy formation in everyday interactions. These studies show the importance of recognizing how much of strategy formation is rooted in the non-deliberate practical action of 'coping' that escapes the logic of planned and intentional action.

This chapter builds upon the distinction between the 'building' and the 'dwelling' modes in order to introduce a narrative approach to Strategy as Practice. We contend that Strategy as Practice research is still mainly imbued with the conceptual categories of the dominant 'building' mode. We propose that the recognition and integration of the 'dwelling' mode into strategy formation, as well as the combination of the 'building' and the 'dwelling' modes in strategy -making, are the key challenges for research analysis. In order to include in the picture the hidden creativity embedded in mundane practical 'coping', closer scrutiny and better accuracy in methodology need to be achieved. We propose a narrative approach to Strategy as Practice. It relates strategy making to using texts and narratives, and also provides the conceptual and methodological means to achieve these challenges. A narrative approach enables strategy research to engage more deeply in the "practice turn' and to develop a 'certain research sensibility to the unspoken, the inarticulate and even the often unconscious aspects of strategy-making' (Chia and MacKay 2007).

This chapter is organized in four sections. The first section describes the various perspectives on narratives brought into strategy research. Beyond the overall functionalist interest in good stories, it shows the importance of texts in strategy and management. The second section, on the basis of the work of Paul Ricœur, develops the implications of this very notion of text. The third section follows Michel de Certeau's analysis of practices to identify a narrative way of forming strategy. In line with Chia's distinction based on Heidegger, we consider producing texts as the dominant 'building' mode of strategy making. This mode is actually derived from a more basic 'dwelling' mode, in which strategy formation emerges through reading texts and producing daily narratives. The last section draws the implications of our conceptual framework of 'strategy-making from texts and narratives', which is based upon the dynamics of reading and writing 'texts'. It offers a perspective in which all organizational actors carry out strategy formation in their daily ordinary activities that interact in multiple ways with texts produced more formally by more powerful stakeholders.

\section{Narratives in strategy research}

Since the publication of Barry and Elmes' (1997) article on the narrative aspects of strategic discourses, it has been generally accepted that strategy - both organizational strategies and theories of strategy - consists of stories told by key people, generally leaders, to other people such as shareholders, members of the organization and other stakeholders. This work highlighted the double nature of strategy - narrative production and process of narration - by which various stories about strategic choices are connected, tested, reinforced or weakened. It also related strategic change processes to the romantic genre, the adventure novel of 
ordeal and to realistic fiction. With a certain degree of irony, the authors underlined the epic, even hagiographic, character of several strategic discourses of leaders. For example, the promotion of neo-Schumpeterian heroes in entrepreneurial strategies created a demiurgic drift in many research accounts of new venture founding (de La Ville 2006).

Why are stories and narratives so interesting? The basic function of a story is to organize a series of events and actors into a common, acceptable and comprehensible temporal framework. By reorganizing events in a temporal framework, stories preserve and build the continuity of actions. The perception of the stakes of the present situation enables us to re organize past events into a story. Restructuring a group of relationships creates retrospective senses, hence enabling further action. This faculty of generating sense has led researchers to become interested in stories told within organizations. Research on organizational culture and identity considers both large stories myths, texts and discourses - and smaller ones such as stories, storytelling, gossip and ... narratives (Gabriel 2000; Boje 1991, 1995; Boyce 1996) as important in analysing and understanding organizational life.

Stories and storytelling have now pervaded management, strategy and marketing research areas (Salmon 2007) and have put in the forefront a new array of consultants and gurus. Good stories are hence considered an effective factor in implementing strategic ideas. Strategy formulation involves a narrative production of an integrative story that enables the leaders to reorganize past events according to a plausible and desirable logic. What is at stake is the capacity of stories to construct a persuasive and stimulating message to facilitate memorization and training or to convince stakeholders of the relevance of a strategy. Leaders need to be good storytellers, i.e. be able to tell good stories which must be both coherent to gain credibility and stimulating to facilitate its reception and implementation. In a functionalist view, the construction of a good story supposes an overall intentionality, meaning total control of the plot through to its final outcome. It does not takes into account such organizational phenomena as improvisations or routine activities, to which it is difficult to attribute intentionality due to their taken-for-granted nature.

Thus, the functionalist view of strategic good stories fails to capture the complexity of strategic processes and practices. It prevents us from widening the field of analysis to include the ordinary narratives of mid to low-level organizational members in relationship with the higher-level 'visionary' strategy produced by senior executives. However, is the intrinsic quality of a good story able to dissolve the integrative difficulties inherent in the strategic exercise? Moreover, can the integrative strategic narrative be considered effective without including the interpretations of people to whom it is addressed? To escape this over-simplistic view of storytelling management, we need to account more accurately for the narrative perspectives brought into strategy research.

For social scientists, the interest in narratives is based on the way people organize knowledge in their daily life. It is suggested that people organize their experience in the form of scripts about goal-based events that include people, places and events, and these scripts are recounted in the form of stories. On the one hand, it seems fairly evident that narrative is a universal form in which people construct, represent and share experience (Bruner 1990). On the other hand, there exists evidence that shows how deep cultural narratives are, how powerful stories are as a socializing agent and, conversely, how much they reveal about the values, beliefs and thought processes of a given culture or community. Bruner (1986), among others, has argued that it is difficult to distinguish between the stories children learn and the stories they build from their direct experience and knowledge. The narrative ability to create stories develops during childhood through reminiscing and engaging in symbolic play (Engel 1995). Narratives do not merely convey fantasies or the representation of unusual feelings or experiences, but also provide a fundamental intra- and interpersonal process, through which children make sense of themselves in the world. Storytelling is a deep social activity and a powerful private activity. Children tell stories when alone, they tell stories that have private meanings, and they use stories as much for their internal thoughts and feelings as they do to communicate. 
What researchers have learned so far is that children create stories in much the same way as they create play scenarios - with the pleasure of creativity. It is important to keep in mind that the form and content of children's stories are tied to the context in which they are told and the purpose for which they are told (Engel 2005).

Following Czarniawska's distinction between three different modes of mobilizing narratives, we acknowledge three narrative perspectives in strategy research. It is possible for the researcher either to build explanations out of 'narratives from the field', or to build his own 'narrative in the field' and even to define 'organising as narration' (Czarniawska 1997, p. 25). The first mode is visible in the interactional perspective developed in communication science, the second is at play when strategy is portrayed as a story of domination and discipline, and the third envisages strategy formation as narration.

\section{Strategic narratives as meta-conversations}

The interactional perspective highlights the vital importance of communication in organizational life in general and strategy formation in particular. For followers of this approach, ordinary activities develop through conversations, which constitute coherent discursive units in themselves. Giroux describes this process as a "chain of conversations' spread out in time and space. She considers a dialogical mode of production of strategy, 'through a polyphonic vision of the community where several voices are heard, and where the heteroglossia (the simultaneous presence of several languages) is accepted' (Giroux 1998, p. 7, our translation). The formulation of strategy is then conceived as a narrative process that organizes polyphony. The concept of polyphony recognizes the coexistence, interaction and mutual definition of various logics. In this polyphonic process, strategy formulation is never controlled by one single author, so it is particularly complex. Strategy is worked out gradually by negotiation within a 'meta-conversation' (Giroux and Demers 1997) dedicated to strategy formation, and leads to the drafting of a strategic text.
Taylor and Robichaud (2004) suggest that for organizational members to interact, they must construct a shared language, embodied in a text which enables them to cooperate. This begins with everyday conversation with mutual interaction, which is a prerequisite of organized activity. The resulting narratives constitute secondary productions, which formalize the interpretations constructed in conversation and carry them toward future actions. Not only does the text produced retain the traces of the original conversations, it frames subsequent actions by offering interpretative frameworks for the sensemaking of ongoing events. This view relates the concept of text to that of the framework of interaction, which is inspired by Erving Goffman and has previously been used in analysing strategy formation (de La Ville 2001).

This proposition is based on the analytical distinction between the two dimensions of discourse as text (what is said) and conversation (what is accomplished in the saying): 'Conversation refers, in other words, to the interactive, situated "eventfulness" of language use; text refers to the semiotic artefact (oral or written) produced in the use of language, which may persist as a trace and record of past conversations' (Robichaud et al. 2004). A meta-conversation is then defined as 'a conversation that embeds, recursively, another conversation' (Robichaud et al. 2004). The meta-conversation simultaneously incorporates and reconstructs the local discussions within the organization into an encompassing conversation, where the identity of the organization as a whole is continuously regenerated. The process at work is the production of a meta-narrative that enfolds and transcends the narratives of the different communities comprising an organization.

\section{Strategic narratives as discourse of domination}

Inspired by the work of Foucault, the critical organizational discourse perspective (Vaara 2002; Philips and Hardy 2002; Fairclough 2005) focuses on discourses as linguistically mediated constructions of social realities. Discourses are important means through which beliefs, values and norms are reproduced and at times transformed in social life 
(Fairclough 2003). This perspective is one of the various approaches to discourse analysis (van Dijk 1997) and to organizational discourse analysis in particular (Hardy and Philips 2004; Grant et al. 2004).

Based on the work of Foucault (1971), this study highlights the disciplining power of discourses on the ordinary practices of organization members, stemming from their capacity to impose and legitimize certain interpretative frameworks at the expense of others. Foucault warns that it is a question 'of no longer treating the discourses as sets of signs (of meaningful elements which refer to contents or representations), but as practices which systematically form the objects about which they speak' (Foucault 1976). Discourses should be considered 'surreptitious objectivations' (objectivations subreptices): they appear to be built by induction and serve to describe the world, but in fact they actually constitute the world. More generally, the language used on a daily basis within an organization is itself a bearer of logics of domination, which direct ordinary interactions and activities and legitimize power relations (Hardy 2004).

Strategy discourse is thus considered to be a complex set of meanings constituting this body of knowledge (Knights and Morgan 1991), as well as a part of the complex set of social practices formulating strategy as an organizational practice. Moreover, discourse analysis enables us to identify how specific conceptions of strategy work are reproduced and justified in organizational strategy formation. The idea that strategy includes a disciplining dimension emphasizes the importance of the stakes of power and legitimization invoked in the strategic exercise.

Critical theorists (Alvesson and Deetz 2000; Putnam and Cooren 2004) offer a different point of view on key documents, such as regulations, procedures and memorandums. Discourses are selected, perpetuated and subsumed in texts, which are registered, preserved and memorized in accordance with the disciplinary function of the organization. These texts do not result from interaction between organization members; they rather influence strategy formulation by virtue of their structured and permanent character that enables organizations to survive (McPhee 2004). Discourses and texts mobilize mechanisms of domination based on legitimized rationality and the invoked scientific nature of the discipline. They result in practices of monitoring and controlling, but also aim at influencing the subjectivity and identity of organization members. Hardy and Phillips (2004) highlight how certain actors are able to mobilize economic, cultural and social capital to legitimize their power. From this point of view, the very notion of discourse includes domination and is opposed to the ordinary, fragmentary, situational narratives being built during the course of the everyday activities of organization members and bearing the stamp of subjectivity and of emotion.

\section{Organizations and strategies as narration}

The claim made by McIntyre (1988) that it is useful to think of an enacted narrative as the most typical form of social life' (Cited in Czarniawska 2002) is adopted in the third view. Czarniawska's (1997) interest is in the daily activities of the organization members, which result in the creation of the organization itself. She identifies two types of conversations: those allowing for the confrontation of personal experience or actions between two parties, and those manufacturing texts beyond the personal experience of the individual by imposing standards of behaviour and decision. This coexistence results in fierce competition between the 'stronger' order - that of the official discourse which reinforces institutional domination by controlling interpretations - and the 'weaker' order that of the ordinary narratives which tries to make sense of daily activities. Her work suggests an ironic stance with regard to the impact of strategists, as she finds strategy to be a relatively artificial discursive construction, far removed from the realities experienced by organization members and geared to institutional concerns for domination and justification. Without any impact on the future of large public organizations and with no control over its daily activities, strategy appears in her description to be a kind of meaningless ritual (de La Ville and Mounoud 2003). The severity of this assessment is partly explained by Czarniawska's focus on public organizations where the distance 
between official discourses and actual practices might be particularly perceptible.

In Czarniawska's view, everyday life within the organization takes shape through ordinary narratives in which individuals select events, organize temporalities, typify key characters, build identity relationships, structure their experience, and construct and transform their interpretations. Drawing on Bruner's point that 'there is an availability, or a predisposition to organise experience in narrative form by building intrigues' (Bruner 1990), we estimate that the continuity of existence may be understood by recounting this same existence, a narrative process of fashioning one another's identities. Through the spoken word, exchanged and retained among themselves, organization members construct and perpetuate their identities and their organized activity. Language, speech, plot production, mere stories and ordinary narrations are experienced and consubstantial with organizing itself. The construction of activities, knowledge and identities is thus structured in and through a complex interlacing of narrative processes, which is always spontaneous, related to unforeseen events and socially organized (Czarniawska 1998).

In the following section, we will study strategy in terms of narration, including narrative production and the process of narration, in which the future is created through a collective narrative that is dispersed and fragmented, being the subject of partial developments, major transformations and inscriptions perpetuated in texts. Strategy-making, when considered as directing the future and leading organization members to comply with this direction, results partly in the production of texts. Nevertheless, not all texts can be qualified as 'strategic', nor is strategy formation confined to the processes of creating or monitoring the effects of 'strategic' texts. We will now consider the implications of this production of texts.

\section{Strategy formation as producing texts}

Strategic texts constitute forms of mediation, in and through which organizational actors reflexively understand their situations, give meaning to their actions, and anticipate their futures. Produced strategic texts thus have a double relation with the context (the preceding texts with which they interact) and the situation (the mundane organizational activities and practices to which they relate and help organize).

\section{Texts organize relationships of intertextuality and polyphony}

The production of a strategic text relies on a group of scriptural prerequisites. To be described as 'strategic', the text must bring together appropriate standards, rules and criteria that explicitly connect it to the discipline of management and to various genres relevant to strategy, such as management reports, business plans, development plans, refocusing plans, asset redeployment plans, etc. Processes of institutionalization accompany and support the production of strategic texts while differentiating them from other textual productions. MBA programmes, specialized academic courses, consulting firms and trade associations legitimize strategists and increase their influence. Strategic activity is seen through textual productions that communicate to shareholders the relevance of the strategic project and the strategic team's control.

Strategic texts are embedded in intertextual relations, with pre-existent strategic texts that are themselves governed by the instituted kinds of organizational productions, and by discursive orders based not only on the scientific advances of management as a discipline (Hardy 2004), but also on objectives and strategies derived from the constitutive values of the local social system. Since strategy formulation is directly embedded in an institutional environment, it inevitably includes an ideological dimension, because it reproduces the inequalities of the capitalist society, extends Western managerial structures and presents the objectives of dominant elites as universal goals. Being institutionally inscribed, strategic texts propose worlds that include a disciplining function founded both on legitimized scriptural standards and on institutionalized value systems.

Because they present a proposal for a relation with the world, strategic texts cannot ignore the multiplicity of voices, actions and narratives within the organization (Giroux and Demers 1997). The 
very production of strategic texts organizes a polyphonic relationship among voices, which always remain singular and develop autonomously, but answer one another, oppose one another and contribute to proposing new worlds (O'Connor 2000; Hardy 2004). Strategy formation proceeds from the application of strategic apprenticeship, which goes beyond the order of discourse and conversation to integrate a body of knowledge into explicit activities and tacit tactics. Furthermore, the ordinary practices of managers and the texts that underlie them, through the resistance that they express, continually nourish the inventiveness of the organizational actions and form an ongoing, emerging and vital part of the strategic activity. Either these practices are gradually recognized, named and defined so as to be integrated into the strategic text, or they remain invisible or exterior (perhaps because they occur outside official channels). Thus, strategic texts operate a selection and organization of mundane organizational narratives.

The notion of 'intertextuality' allows us to appreciate writing as a permanently creative flux integrating previous standards and conventions in order to produce texts, which are likely to be readable, understandable and recognizable by an audience. It was described by Julia Kristeva (1980, p. 69) as a reaction to the tendency to analyse texts as discrete and closed units, whose meaningfulness lay in their internal structure. Drawing on the dialogue perspective proposed by Mikhail Bakhtin (1968) in literary theory, she contends that texts become meaningful if they are considered as a fragment relating to former texts. Shared codes allow both the writer and the reader to recognize, situate and appreciate the text in the continuum of literary production. It is worth noting that this post-structuralist perspective considers that every text is under the dominance of previous texts that impose a universe of codes in relation to which it will be read and understood by certain audiences. This suggests a drastic shift in the method of analysing reading and writing by focusing the effort on studying the process of structuration through which the text comes into being. By questioning the romantic roots that lead to the invention of the notion of 'authorship', this perspective lays special emphasis on the fact that writers are compelled to use pre-existing concepts and conventions to communicate with an audience. When speaking they are at least partially expressed and their individual creative skills are socially founded in shared language and scriptural conventions. That is why Roland Barthes defines text as a tissue of quotations, a creative art consisting in weaving former codes, references and genres (Barthes 1974).

Texts draw upon a large range of codes and social norms that allow them to be assigned to a particular genre. Genres are situated and evolving conventions that enable us to classify texts and outline their relationship with each other. Literary theorists have brilliantly demonstrated that the definition of genres is quite fluid and relates to ongoing changes and social renegotiations, leading to a permanent blurring of borders and a constant mitigation of their distinctive characteristics. We are fully aware that such a brief presentation of the complexities linked to the notion of 'intertextuality' and its use in cultural studies and literary analysis is a risky undertaking. Nevertheless, in the context of this chapter, we aim at transposing this notion into a managerial perspective, in an attempt to offer some guidelines to support managers' efforts in mastering the complex stakes of 'intertextuality' needed to exploit strategically the creativity hidden in mundane organizational activities.

\section{Texts call for reading}

To analyse the dynamics of texts, we draw on Paul Ricœur, for whom the concept of text covers a limited category of signs: those which comprise a form of fossilization comparable with that produced by writing (Ricœur 1991) because the latter allows the conservation and the linearization of the conversation. When writing is added to a previous statement, it modifies the relationship with the utterances, which is called the 'ostensive reference' by Ricœur, i.e. the object with which one expresses oneself. Writing creates a different relationship from that of interlocution: the reader is absent from the writing and the author from the reading. The text is thus the product of a simultaneous eclipsing of the reader and the author. In this 
view, the nature of the text is underlined. Because of its fossilization into a medium, because of the lack of association between the intention of the author and the intention of the text, because of the use of 'non-ostensive' references and the substitution of unknown readers for a visible listener, the text must be differentiated from a face-to-face or situated discourse.

Consequently, 'the text awaits and calls for reading' (Ricœur 1991). Ricœur distinguishes two ways of understanding reading: to explain and to interpret. 'To explain is to bring out the structure, i.e. the internal relations of dependence, which constitute the static of the text. To interpret is to follow the path of thought opened up by the text and to start heading towards the orientation of the text' (Ricœur 1991). This dualism suggests a dialectic in the activity of reading, as movement between these two attitudes produces interpretation. The open nature of the text is made salient: references are offered to propose a 'world' and build a new project. Reading is possible because text is not closed in on itself; it is open to other things. Reading is thus a creative activity that prolongs the creation of writing. As stated by Ricœur (1991), 'to read is, in any hypothesis, to conjoin a new discourse to the discourse of the text'.

Strategic texts are characterized by their plurivocity: their significance is unresolved and each text, because of the distance caused by its written form, is open to alternative readings and constructions depending on the situations of readers. Interpreting strategic texts, organizational actors propose their relations with the world. This process of appropriation, which takes place in the narrative register, as we will show in the next section, is complex, dense, emergent and dynamic.

We have underlined the 'building' mode of strategy formation as producing strategic texts. It is important to keep in mind that these texts are themselves embedded in a 'context' of previous texts and are derived from the polyphony of situated narratives. It is now possible to envisage the more basic 'dwelling' mode of strategy formation, the everyday practical 'coping' with the rules and the texts of the organization. The relationship of this 'dwelling' mode with the 'building' one is similar to that of reading with writing.

\section{Narratives as practical coping with strategic texts}

The creativity of reading is shared by Michel de Certeau, who argues for a greater emphasis on the activity of reading to oppose the excessive importance placed on writing in contemporary society, a society that he finds 'increasingly written, organised by the capacity to modify things and to reform the structures through scriptural models (scientific, economic, political), and gradually transformed into combined "texts" (administrative, urban, industrial, etc.)'. He strives to show that reading is not a passive activity; it modifies its object, reinvents beyond the intention of the text, and builds a different 'world', which belongs to the reader in place of the author, 'to make the text liveable'. Readers carry out 'a reappropriation of the other's text: he poaches there, he is transported there, he becomes plural there' (de Certeau 1988).

\section{Reading as consuming texts}

According to Michel de Certeau, everyday life is distinctive from other practices of daily existence because it is repetitive and unconscious. An interesting point is the distinction he makes between the concepts of strategy and tactics. De Certeau links 'strategies' with institutions and structures of power, while 'tactics' are utilized by individuals to create space for themselves in environments defined by strategies. In one chapter, he describes 'the city' as a 'concept', generated by the strategic manoeuvring of governments, corporations and other institutional bodies, who produce things like maps that describe the city as a unified whole experienced by someone looking down from high above. By contrast, a walker on the street moves in ways that are tactical and never fully determined by the plans of organizing bodies. He may take shortcuts or meander aimlessly, rather than follow the utilitarian layout of the grid of streets. This concretely illustrates de Certeau's assertion that everyday life works by a process of poaching on the territory of others, recombining the rules and products that already exist in culture in a way that is influenced, but never wholly determined, by those rules and products. 
For de Certeau, consumption supposes the acceptance of an offer of products. But consumers are active; they take pleasure in consuming and consider themselves free and creative in doing so. Under the apparent banality of ordinary gestures and routine actions lurks an extraordinary creativity often ignored by theory. Individuals show a great capacity for 'making do'. They exhibit inventiveness in terms of shrewd ploys and stratagems to work out their own way of doing things, whether it is cooking, strolling through a town or shopping, etc. Being analysed superficially, certain routine behaviours reveal a form of submission. Through in-depth analysis, they reveal ongoing experimentations filled with resistance and creativity. The relationship between reading and writing is of a comparable nature: texts, just like the goods offered on the market, are produced by manufacturers who offer them to consumers - the readers who decide upon their significance and use them in their own ways.

De Certeau's analysis of consumption is oriented towards the ordinary practices of consumers, who are defined as 'users of goods imposed upon them by producers'. Indeed, in offering products to consumers, producers assume a position of domination, against which consumers resist by developing inventive attitudes and practices. By mirroring consumption and reading, de Certeau reveals the two sides of consumption. On the one hand, consuming entails a form of acceptance of an imposed offer of goods. On the other, consumers are neither passive nor docile; they experience freedom, creativity and pleasure - just as readers do. Commenting on empirical investigations of several situational social practices such as reading, talking, dwelling, cooking, wandering around, etc., de Certeau explores scientific literature in order to clarify the purpose of his theoretical undertaking:

It may be supposed that these operations multiform and fragmentary, relative to situations and details, insinuated into and concealed ... within devices, whose mode of usage they constitute, and thus lacking their own ideologies or institutions - conform to certain rules. In other words, there must be a logic of these practices. (de Certeau 1988)

\section{Narrativity in strategy formation}

Thus, strategy making can be understood as a permanent creative process including not only what strategists produce/write, such as texts, budgets, plans, matrices, charts and strategies, but also the ways in which organization members consume/ read these productions. This conceptual framework leads us to question how organizational actors read, use and transform strategic texts in their daily activities. Reading takes place through the mobilization of innumerable fragmentary, instantaneous, opportunistic tactics (de La Ville and Mounoud 2001b). 'These tactics also demonstrate the degree to which intelligence is inseparable from the struggles and the daily pleasures which it articulates [...] Because of its intangible nature, a tactic depends on time and remains vigilant to catch any possibilities of profit. It does not keep what it gains. It is necessary for it to play constantly with the events to transfer them into opportunities' (de Certeau 1988). Being incapable of capitalizing voluntarily on their achievements to control temporality and the course of events, these tactics, which are peculiar to the art of reading, may produce tangible and sometimes irreversible strategic effects, such as delays in implementation, side-tracking from the main objectives, operational diversions, more or less continuous symbolic rejections or the subversion of authority.

Adopting this view provides a new way of looking at organizational practice, because it enables us to accept strategic discourses as a production and an offer of a (cultural) good: a text. Thus, we might be able to suggest new ways of explaining how people read, use and transform this particular cultural product. Linstead and Grafton-Small (1992) contrast the production of corporate culture with the creative consumption of organizational culture by organization members. Using this conception requires supplementing the analysis of the discourse of strategy (representation) and of the time spent attending strategic meetings (behaviour) with a study of what middle managers and employees actually 'make' or 'do' during that time and how they use these discourses. With their 'making' or 'doing' being devious and dispersed, it remains difficult for the researcher to analyse. 
In organizations, employees and managers do not adopt, adhere to or share the 'strategic' vision or intent of their 'charismatic leaders'. In their everyday activities, they actively interpret, criticize, learn and experiment with possible attitudes and micro-decisions in order to implement or resist the multiple implications of strategic changes imposed on them.

Practice expresses creativity, a capacity 'to put up with', to subvert imposed rules and create room for manoeuvre. Practice includes the subconscious part of creativity, seen in clever devices and inventions. This creativity is also evident in attempts to negotiate meanings of actions and events among organization members, i.e. in ordinary and everyday narratives. The narrative register indeed enables the practical art to express itself, to experiment, to improvise and to resist the domination of a disciplining totality envisioned by some strategic texts. De Certeau identifies three places where this practical creativity of ordinary accounts can be seen: the 'games' that formalize the organizing rules of 'actions', the 'game texts' that teach the practices available, and tales and legends that expose the available good and evil tricks. This aspect of consumption, included in strategic activity because of its dispersion, surreptitiousness and deviousness, evades the eye of both the researcher and the manager.

This reading - or consumption - of strategic texts constitutes a second-order production, which de Certeau calls a fabrication, i.e. a narrative which is added to the intention of strategic texts. Employees often do not adhere to, embrace or share the strategic vision or the worlds produced by strategists or top management. In their daily activities, managers and employees learn, test and demonstrate critical thinking to take micro-decisions, be they to implement or resist strategic mandates. This conceptualization makes it possible to comprehend the complexity and the creativity of strategy formation and to reconsider the problematic bond between the 'emergent' and the 'deliberate'. On the one hand, processes of institutionalization accompany and support the emergence of integrative organizational discourses that become strategic texts. On the other, innumerable readings ensue in a disorderly way, gradually giving shape to a multiplicity of tactics that constitute strategic practice.

\section{Implications for research}

As summed up in Figure 12.1, we have defined strategy formation as both producing strategic texts and reading them, thus, as producing daily narratives. The writing of strategic texts implies the use of standards, which authorize the inscription of the text in the strategic genre. Strategic texts are based on the institutional ruling order and combine together to produce the dominant discourse of strategy. Strategic texts also proceed from a selection and polyphonic organization of mundane organizational narratives. But strategy formation also includes the creative reading of strategic texts, producing unpremeditated tactics for resisting their domination. It is important to study the consumption side of strategy making.

The central concept of plot developed by Paul Ricoeur helps us to bring to light the various narratives produced while organizational member consume dominant discourses, strategic texts and formal procedures, etc. [...] Ricoeur (1984) built his concept of 'emplotment' (mise en intrigue) around Aristotle's sentence that 'the plot is the imitation of the action - for by plot, I here mean the arrangement of the incidents' (Poetics, part VI). For Ricoeur, the narrative defined as 'emplotment' combines the Aristotelian concepts of mimesis (imitation) and muthos (arrangement of the incidents): 'With the narrative, the semantic innovation consists in the invention of a plot, which is also a work of synthesis: through the plot, objectives, causes, incidents are brought together under the temporal unity of an action that is complete and whole' (Ricoeur, our translation). Thus, narrative is defined as a 'synthesis of the heterogenous'. The concept of 'emplotment' may be used to identify how the main plot or story-line is read in different narratives. These reading practices revealed by narratives can be reconstructed by the researcher from qualitative inquiry based upon observations and conventional unstructured and semi-structured interviews as well as from archival data. The narrative perspective gives way to the analysis on the 


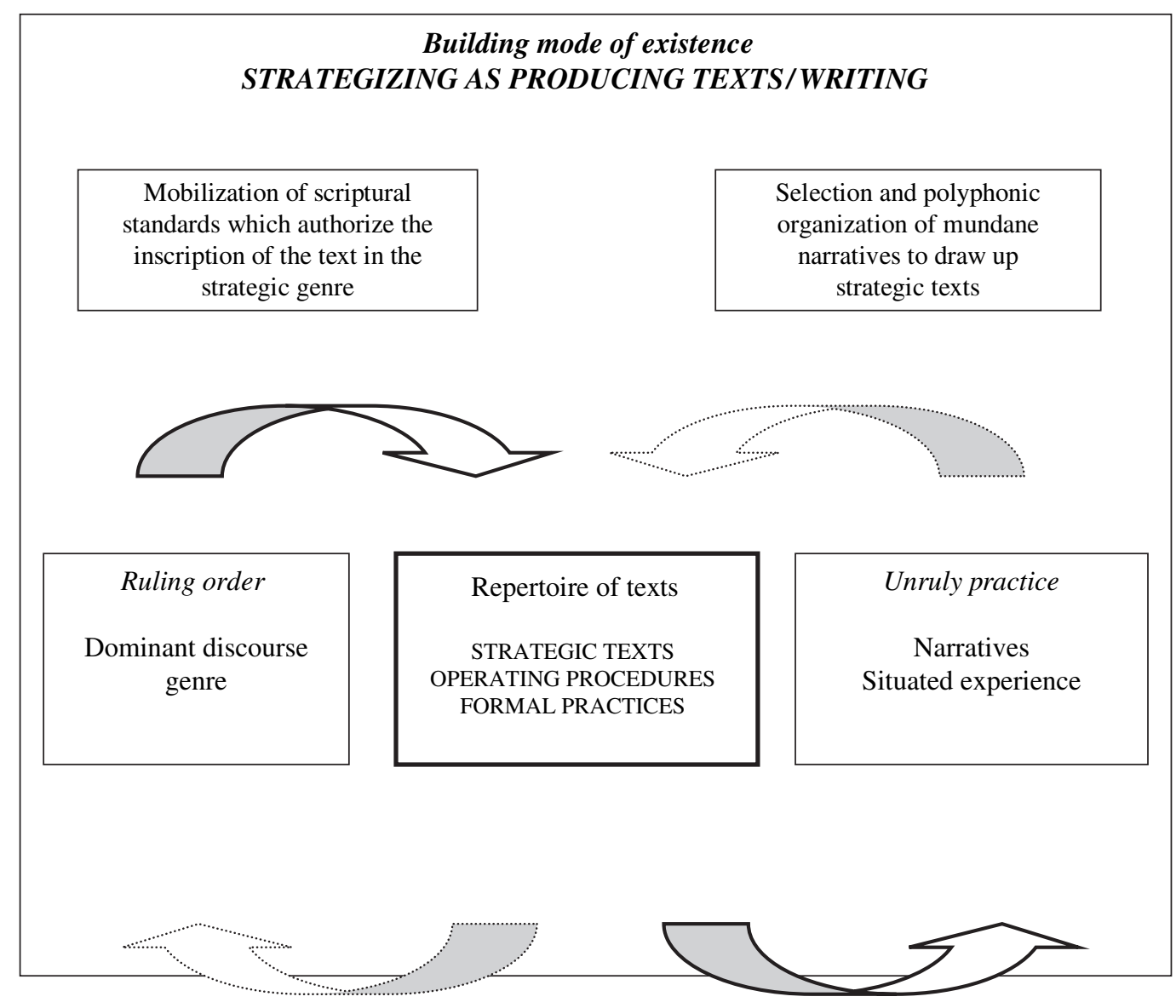

Intertextual relationship which positions the text with regard to previous strategic texts

Creative reading of strategic texts and tactics for resisting their domination

\section{STRATEGIZING AS CONSUMING TEXTS/READING \\ Dwelling mode of existence}

Figure 12.1 Strategy making from texts and narratives 
Table 12.1 A consumption perspective on strategy formation

Consumption/Production

Ruling order: institutional environment

Producing dominant discourses / Consuming social practice

Strategic texts and formal practices

Unruly practice
Producing strategic texts and formal practices / Consuming dominant discourses

Consuming strategic texts and formal practices: the consumers' stories / producing social practice consumption/production interplay across three levels of analysis as shown in Table 12.1.

Under the label 'formal practices', we mainly include the tools, techniques, norms and routines used in everyday activity to do things. Such practices fit Jarzabkowski's (2004, p. 545) definition of a specific subset of practices: 'those management tools and techniques present in macro-institutional and competitive contexts, arising from co-production within different communities of practice, that is, industry, academia, consultancy, and the press, each with some common points of discourse'. They are diffused through the teachings and research of business schools, the use by consultancy firms, and through management fashion (Abrahamson 1996), in which the popular press plays also a role.

The consumption of dominant discourse, strategic texts and formal practices can be tracked within the management fashion framework (Corbett \& Mounoud forthcoming; Abrahamson 1996; Sturdy 2004). Such an analysis then encompasses rhetorical approaches (i.e. what direction is conveyed in the official discourse), as well as political views focusing on the instrumental use of strategies to secure power, and cultural perspectives highlighting the impact of corporate culture. A rhetorical approach looks at the language and arguments used to convince an audience. Rhetoric can appeal to rationality: strategies are adopted because 'they work or promise to do so'. But it can also appeal to emotions. New strategies are adopted not because of their supposed effectiveness, but rather because they 'provide a potentially comforting sense of order and identity and/or control' (Sturdy 2004). Rhetoric can also refer to the language devices and tricks used by management gurus and other suppliers of ideas to convince the somewhat naïve manager to adopt a new practice.
In such a 'dramaturgic' perspective, managers are often portrayed as puppets in the hands of cunning strategists. By contrast, the political view gives an active role to those adopting new management ideas or practices. This view is concerned with the instrumental use of ideas/practices to secure power, and/or with their content in terms of their material and/or discursive power. The political view also highlights contestation, tensions and resistance to the adoption of management ideas, whilst the cultural view focuses on the local embeddedness of ideas and practices. Culture - here the organization's culture - can be either a bridge or a barrier to the transfer of some management ideas and practices. Focusing on daily practice allows us to grasp all the contradictions and tensions of daily activity. Individuals are able to play with the rules and to use the artefacts of everyday practice at their own ends. Actors are also full of intent in their use of these practices and the intent of the actor may not comply with the objective purpose of a particular practice. Thus, the properties of a practice are open to interpretation according to the use to which they are put (Jarzabkowski 2004). Practice is the singular art of coping through combination, inventiveness and 'Do it yourself !' techniques, i.e. 'a way of thinking invested in a way of acting [...] which cannot be dissociated from an art of using' (de Certeau 1988).

\section{Conclusion}

Drawing from the narrative perspective in organization studies, we address the strategic role of mundane stories and narratives that give meaning to daily experiences and enable cooperation. In particular, we consider the fundamental role of 
reading as a process of comprehension and application of texts. We propose a model for strategy formation that states how strategic texts are created recursively, starting from the mundane narratives which influence daily practices (de La Ville and Mounoud 2001a). We also clarify the relationships that these mundane narratives have with texts produced by other stakeholders. The strategic text is thus involved in a double relationship with the context (the body of the preceding texts to which it relates) and with the situation (the ordinary activities it accounts for and helps organize). This framework highlights the mediation role of strategic texts between institutional contexts and organizational situations and clarifies the processes involved in strategic textual productions. Strategy making has much to do with the capacity to master the skills of discussion. However, the practice aspect of strategy-making appears to be immersed in the narration of human experience. We consider strategic documents that organizations produce, such as written plans, as texts. Thus, they may be considered as 'being read' by organization members. Understanding strategy making based on reading and writing is useful in order to understand the complexities of strategy formation.

Strategy formation brings into play complex processes of interaction between organizational productions of a contrasting nature. It may be understood by using the text as a model of "judicious" or sensible action. The latter 'becomes a subject of science on the condition that a kind of objectivity equivalent to the fossilization of the discourse through writing exists' (Ricœur 1991). Ricœur thus equates ordinary action with speech and conversation: action is also a representation anchored in the present, whose structure resembles that of speech, acts and utterances. Conversely, the judicious action, associated with strategic action, perpetuates itself, leaves traces and becomes memorable. An action leaves its mark when it contributes to the emergence of significant configurations. A process of recording transforms it into a 'document' or 'archive' of organizational action, which brings it closer to the textual form and distinguishes it from the conversation. The judicious action results from emancipation with regard to the initial context and develops meanings that can be actualized or completed under new and different circumstances. Consequently, the analysis of strategy formation must not be centred only on the conversations or the interactions described as 'strategic'. Strategy making should be considered as the combination of the production of texts and their creative consumption in daily activities. Consumption can be understood as the dominated production of secondorder narratives. The descending order of the dominant discourse of strategy and the ascending order of the resisting narrative, the two realms of strategy making, make the strategic texts their point of intersection and articulation. This meeting shows the complexity of strategy formation. The context dominates and informs the strategic text because it provides the rules for it to form itself. In return, the strategic text, fuelled by ordinary accounts of organization members' practices, is subject to creative readings and resistant consumption. "Human action is open to whoever can read" (Ricœur 1991). Through this double role of mediation, the strategic text gathers meaning and becomes effective.

\section{References}

Abrahamson, E. (1996), 'Management fashion', Academy of Management Review, 2/1: 254-285.

Alvesson, M. and Deetz, S. (2000), Doing critical research management. London: Sage.

Bakhtin, M. (1968), Rabelais and his world. Cambridge, MA: MIT Press.

Barry, D. and Elmes, M. (1997), 'Strategy retold: Toward a narrative view of strategic discourse', Academy of Management Review, 22/2: 429-452.

Barthes, R. (1974) S/Z: An Essay. An Essay.London: Cape.

Boje, D. M. (1991), 'The storytelling organisation: A study of story performance in an office-supply firm', Administrative Science Quarterly, 36: 106-126.

(1995), 'Stories of the storytelling organization: A postmodern analysis of Disney as "Tamaraland", , Academy of Management Journal, 38/4: 997-1035.

Boyce, M. (1996), 'Organisational story and storytelling: A critical review', Journal of Organisational Change, 9/5: 5-26.

Bruner, J. S. (1986), Actual minds, possible worlds. Cambridge, MA: Harvard University Press. 
(1990), Acts of meaning. Cambridge, MA: Harvard University Press.

Chia, R. and Holt, R. (2006), 'Strategy as practical coping: A Heideggerian perspective', Organisation Studies, 27/5: 635-655.

Chia, R. and MacKay, B. (2007), 'Post-processual challenges for the emerging strategy-as-practice perspective: Discovering strategy in the logic of practice', Human Relations, 60/1: 217-242.

Corbett, I., and Mounoud, E. (forthcoming), 'Looping the loop: The consumption and production of knowledge management ideas and practices', Management Learning, Special Issue: The (co) -consumption of management ideas and practices.

Czarniawska, B. (1997), Narrating the organisation - Dramas of institutional identity. Chicago: The University of Chicago Press.

(1998), 'A narrative approach to organisation studies', Qualitative Research Methods Series, 43, Thousand Oaks,CA: Sage Publications.

(2002), 'Interviews and organisational narratives', in Gubrium J. F. and Holstein J. (eds.), Handbook of interviewing. Thousand Oaks, CA: Sage, 733-749.

de Certeau, M. (1988), The practice of everyday life. Berkeley, CA: University of California Press.

de La Ville, V. I. (2001), 'L'actualisation collective des pratiques stratégiques', in Drisse (ed.), Le management stratégique en représentations. Paris: Ellipses, 113-148.

(2006), 'Collective learning processes in high tech firms: Enablers and barriers to the innovation process', in Bernasconi M., Harris S. and Monsted M. (eds.), High tech start-up Creation and development of technology based firms. London: Routledge, 69-85.

de La Ville, V. I. and Mounoud, E. (2001a), 'Narrating the practice of 'strategy': In search of a genre...'. Paper presented at the European Group for Organisation Studies (EGOS) $X V I I^{\circ}$ International Colloquim, Lyon, 5-7 July.

(2001b.), 'The tactics of strategising: A very ordinary perspective'. Paper presented at the Workshop Micro-strategy and strategising, EIASM, Brussels, 1-3 February.

(2003), 'Between discourse and narration: How can strategy be a practice?', in Czarniawska, B. and Gagliardi, P. (eds.), Narratives we organise by. Amsterdam: John Benjamins, 95-113.

Engel, S. (1995), The stories children tell. New York: W.H. Freeman.
(2005), 'Narrative analysis of children experience', in Greene, S. and Hogan, D. (eds.), Researching children's experience-Methods and approaches. London: Sage, 199-216.

Fairclough, N. (2003), Analyzing discourse: Textual analysis for social research. London: Routledge.

(2005), 'Critical discourse analysis, organisational discourse, and organisational change', Organisation Studies, 26: 915-939.

Foucault, M. (1971), L'ordre du discours (Paris: Gallimard). Inaugural speech at the College de France referred to as The order of the speech, in the anglo-saxon literature.

(1976), The archeology of knowledge. New York: Harper and Row.

Gabriel, Y. (2000), Storytelling in organisations Facts, fictions and fantasies New York: Oxford University Press.

Giroux, N. (1998), 'La communication dans la mise en œuvre du changement', Management International, 3/1: 1-14.

Giroux, N. and Demers, C. (1997), 'Communication organisationnelle et stratégie', Management International, 2/2: 17-32.

Grant, D., Hardy, C., Oswick, C. and Putnam, L. L. (2004) (eds.), Handbook of organisational discourse. London: Sage.

Hardy, C. (2004), 'Scaling up and bearing down in discourse analysis: Questions regarding textual agencies and their context', Organisation, 11/3: 415-425.

Hardy, C. and Philips, N. (2004), 'Discourse and power', in Grant D., Hardy C., Oswick C. and Putnam L. L. (eds.), Handbook of organisational discourse. London: Sage, 299-316..

Hendry, J. and Seidl, D. (2003), 'The structure and significance of strategic episodes: Social systems theory and the routine practices of strategic change', Journal of Management Studies, 40/1: 175-196.

Jarzabkowski, P. (2004), 'Strategy as practice: Recursiveness, adaptation and practices-in-use', Organisation Studies, 25/4: 529-560.

Jarzablowski, P. (2005) Strategy as practice: An activity-based approach. London: Sage.

Knights, D. and Morgan, G. (1991), 'Corporate strategy, organisations and subjectivity: A critique', Organisation Studies, 12/2: 251-273. 
Kristeva, J. (1980), Desire in language: A semiotic approach to literature and art. New York: Columbia University Press.

Linstead, S. and Grafton-Small, R. (1992), 'On reading organisational culture', Organisation Studies, 13/3: 331-355.

McIntyre, A. (1988), Whose justice? Which rationality? London: Duckworth.

McPhee, R. (2004), 'Text, agency and organisation in the light of structuration theory', Organisation, 11/3: 355-371.

O'Connor, E. (2000), 'Plotting the organisation: The embedded narrative as a construct for studying change', Journal of Applied Behavioral Sciences, 36/2: 174-192.

Pascale, R. (1984), 'Perspectives on strategy: The real story behind Honda's success', California Management Review, 26/3: 47-72.

Philips, N. and Hardy, C. (2002), Discourse analysis: Investing processes of social construction. London: Sage.

Putnam, L. L. and Cooren, F. (2004), 'Alternative perspectives on the role of text and agency in constituting organisations', Organisation, 11/3: 323-333.

Regnér, P. (2003), 'Strategy creation in the periphery: Inductive versus deductive strategy making', Journal of Management Studies, 40/1: 57-82.

Ricoeur, P. (1984), Time and narrative, trans. by K. McLaughlin and D. Pellauer. Chicago: The University of Chicago Press.

(1991), From text to action: Essays in

Hermeneutics II, trans. by K. Blamey and J.

B. Thompson. Evanston, IL: Northwestern University Press.

Robichaud, D., Giroux, H. and Taylor, J. R. (2004), 'The meta-conversation: The recursive property of language as the key to organizing', Academy of Management Review, 29/4: 1-18.
Rouleau, L. (2005), 'Micro-practices of strategic sense-making and sense-giving: How middle managers interpret and sell change everyday', Journal of Management Studies, 42/7: 1413-1442.

Salmon, C. (2007), Storytelling, la machine à fabriquer des histoires à formater les esprits. Paris: La Découverte.

Samra-Fredericks, D. (2003), 'Strategising as lived experience and strategists' everyday efforts to shape strategic direction', Journal of Management Studies, 40/1: 141-174.

Schatzki, T. R. (2005), 'The sites of organisations', Organisation Studies, 26/3: 465-484.

Spender, J. C. (1989), Industrial recipes. Oxford: Blackwell.

Sturdy, A. (2004), 'The adoption of management ideas and practices: Theoretical perspectives and possibilities', Management Learning, 35/2: 155-179.

Taylor, J. R. and Robichaud, D. (2004), 'Finding the organisation in the communication: Discourse as action and sensemaking', Organisation, 11/3: 395-413.

Tsoukas, H. (1994), 'What is management? An outline of a metatheory', British Journal of Management, 5/4: 289-301.

Vaara, E. (2002), 'On the discursive construction of success/failure in narrative of post merger integration', Organisation Studies, 23: 211-248.

van Dijk T. A.(1997), Discourse as social interaction. London: Sage.

Whittington, R. (2007), 'Strategy practice and strategy process: Family differences and the sociological eyes', Organisation Studies, 28/10: 1575-1586.

Willmott, H. (1997), 'Rethinking management and managerial work: Capitalism, control and subjectivity', Human Relations, 50/11: 1329-1340. 
